\title{
High expression of Aldolase A predicts poor survival in patients with clear-cell renal cell carcinoma
}

\author{
Ning $\mathrm{Na}^{1, *}$ \\ Heng $\mathrm{Li}^{1, *}$ \\ Chengfang $\mathrm{Xu}^{2, *}$ \\ Bin Miao' \\ Liangqing Hong' \\ Zhengyu Huang' \\ Qiu Jiang ${ }^{3}$ \\ 'Department of Kidney \\ Transplantation, ${ }^{2}$ Department of \\ Obstetrics and Genecology, The Third \\ Affiliated Hospital of Sun Yat-sen \\ University, ${ }^{3}$ Department of Organ \\ Transplantation, The First Affiliated \\ Hospital of Sun Yat-sen University, \\ Guangzhou, Guangdong, People's \\ Republic of China \\ *These authors contributed equally \\ to this work
}

\author{
This article was published in the following Dove Press journal: \\ Therapeutics and Clinical Risk Management \\ 27 February 2017 \\ Number of times this article has been viewed
}

\begin{abstract}
Background: Aldolase A (ALDOA) is a glycolytic enzyme that drives the glycolytic metabolic pathway in mammalian cells. The overexpression of ALDOA was observed in a variety of cancers including clear-cell renal cell carcinoma (ccRCC). However, little was known about the clinicopathological significance and prognostic value of ALDOA in ccRCC patients.

Methods: The expression of ALDOA was detected using immunohistochemical staining in 162 formalin-fixed, paraffin-embedded ccRCC sections. Prognostic outcomes correlated with ALDOA were examined using Kaplan-Meier analysis and the Cox proportional hazards model.

Results: In patients with ccRCC, increased cytoplasmic ALDOA expression was positively associated with tumor size $(P=0.021)$, TNM stages $(P=0.034)$, lymph node metastasis $(P=0.020)$, and overall survival $(\mathrm{OS})(P<0.001)$. Kaplan-Meier analysis showed that high cytoplasmic expression of ALDOA was associated with a statistically significant lower OS $(P<0.001)$. Multivariate analysis demonstrated that ALDOA expression was an independent and significant prognostic factor $(\mathrm{HR}=3.561,95 \% \mathrm{CI}=1.715-7.396, P=0.001)$. ALDOA expression was not associated with significant prognostic deference in the subgroups of TNM stage I patients or pT1 patients.
\end{abstract}

Conclusion: Our results suggest that ALDOA expression is an independent prognostic factor for OS in patients with ccRCC.

Keywords: renal carcinoma, Aldolase A, glycolysis, prognosis

\section{Background}

Renal cell carcinoma (RCC), the most common type of kidney cancer, accounts for approximately $3 \%$ of all adult malignancies. Surgery remains the first treatment for localized RCC. However, around $20 \%-30 \%$ of subjects undergoing surgery will suffer recurrence, which often leads to a poor prognosis. ${ }^{1,2}$ Although several existing prognostic systems and models have been established with considerable prognostic ability, they still need to be improved. In recent years, there has been a growing interest in identifying novel tumor markers not only for diagnostic purposes but also to improve the prediction of prognosis. ${ }^{3,4}$ Combining the molecular biomarkers with conventional models might provide more individualized diagnosis and treatment based on molecular characteristics of the tumor..$^{5-7}$

The Warburg effect, a phenomenon characterized by increased aerobic glycolysis of glucose to lactate in the presence of sufficient oxygen, is now known to be enhanced in many kinds of cancers and to play a key role in tumorigenesis and tumor progression. ${ }^{8,9}$ Reliance on aerobic glycolysis was identified as a common feature in sporadic and hereditary forms of kidney cancer, including clear-cell RCC (ccRCC). ${ }^{10-13}$
Correspondence: Qiu Jiang

Department of Organ Transplant, The First Affiliated Hospital of Sun Yat-sen University, Guangzhou, Guangdong Province 5I0630, People's

Republic of China

Tel +862087340600

Fax +86 2087306082

Email qiujiang_sysu@126.com
Therapeutics and Clinical Risk Management 2017:13 279-285

279

Dovepress if in 0

http://dx,doi.org/10.2147/TCRMS123199 (c) (7) (5) $2017 \mathrm{Na}$ et al. This work is published and licensed by Dove Medical Press Limited. The full terms of this license are available at https://www.dovepress.com/terms.php
and incorporate the Creative Commons Attribution - Non Commercial (unported, v3.0) License (http:///creativecommons.org/licenses/by-nc/3.0/). By accessing the work you BY NC and incorporate the Creative Commons Attribution - Non Commercial (unported, v3.0) License (http:///creativecommons.org/licenses/by-nc/3.0/). By accessing the work you
hereby accept the Terms. Non-commercial uses of the work are permitted without any further permission from Dove Medical Press Limited, provided the work is properly attributed. For permission for commercial use of this work, please see paragraphs 4.2 and 5 of our Terms (https://www.dovepress.com/terms.php). 
Aldolase A (ALDOA) is a key enzyme in glycolysis responsible for catalyzing the reversible conversion of fructose-1,6-bisphosphate to glyceraldehyde-3-phosphate and dihydroxyacetone phosphate. ${ }^{14}$ Increased expression of ALDOA has been found in a variety of cancers, such as lung cancer, ${ }^{15,16}$ pancreatic ductal adenocarcinoma, ${ }^{17}$ and hepatocellular carcinomas. ${ }^{18}$ Notably, decades ago, studies had identified an enhanced level of ALDOA in both cancer tissues and peripheral blood of patients with renal carcinoma. ${ }^{19,20}$ However, the significance of ALDOA in prognosis of renal carcinoma remains unclear.

In this study, we examined the expression pattern of ALDOA and investigated its clinicopathological and prognostic significance in nonmetastatic ccRCC tissues of patients who received surgery, in order to study its potential utility as a diagnostic marker and to develop a better understanding of its role in ccRCC.

\section{Methods}

\section{Patients and samples}

Paraffin-embedded primary specimens were obtained from 162 ccRCC patients with complete clinicopathologic data with protocols approved by the Institutional Review Boards of Sun Yatsen University. The patients were diagnosed with localized or locally advanced ccRCC at the First Affiliated Hospital or the Third Affiliated Hospital of Sun Yat-sen University between 2003 and 2004. The histological cell types of all samples were determined by experienced pathologists, and all of them were diagnosed as conventional ccRCC. The clinical stage of ccRCC patients was evaluated on the basis of the TNM classification system. The inclusion criteria for patients were as follows: 1) initial treatment including radical nephrectomy by either open approach or laparoscopy, 2) pathological confirmation of ccRCC by postoperative histopathology diagnosis, 3) no radiotherapy or chemotherapy before surgery, and 4) without distal metastasis. Patients who died of postoperative complications were excluded. Details of clinical and pathological characteristics were collected for each patient. This study was approved by the Institutional Ethics Review Committee of Sun Yat-sen University, and written informed consents were obtained from all patients involved in the study.

\section{Immunohistochemistry}

Sections of paraffin-embedded specimens were baked and deparaffinized in xylene and rehydrated in a grade series of ethanols, followed by microwave antigen retrieval. The activity of endogenous peroxidase was exhausted, and then rabbit ALDOA polyclonal antibody (HPA004177, Sigma, St Louis, MO, USA) was applied overnight at $4^{\circ} \mathrm{C}$ at an optimal working concentration of 1:1,000. After sufficient phosphate-buffered saline rinses, sections were stained with goat antirabbit polymers. Subsequently, the sections were stained with 3,3'diaminobenzidine (DAB). Staining was scored by two independent investigators who were blinded to the clinicopathological and prognostic data. The staining intensities (scored from 0 to 3 ) and the percentage of stained cells (scored from 0 to 100 ) were evaluated in ten randomly selected high power fields. A semiquantitative immunohistochemical (IHC) score was applied by calculating the product of staining intensities and staining extent, and then a final total score ranging from 0 to 300 for each sample was obtained. The median score was chosen as the cutoff value to define the low and high ALDOA expression cases.

\section{Statistical analysis}

Statistical Product and Service Solutions software package 17.0 (SPSS Inc., Chicago, IL, USA) was used to perform statistical analysis in the study. Frequency distributions were compared by chi-square test or Fisher's exact test. Continuous variables were compared using the Student's $t$-test. Kaplan-Meier survival analysis was used to assess the overall survival (OS), and the significant differences between survival curves were determined by the log-rank test. The prognostic effects of variables were identified by univariate and multivariate Cox proportional hazards regression analysis. Variables that were found to be significant on univariate analysis at $P \leq 0.05$ were included in multivariate analysis. Cox proportional hazards models were generated for multivariate analysis. All $P$-values $<0.05$ were considered of statistical significance in a two-tailed test.

\section{Results}

\section{ALDOA expression in human ccRCC}

The immunohistochemical staining of ALDOA was predominantly located in the cytoplasm in tumor tissue. The representative images for negative, low, and high immunostaining of ALDOA are shown in Figure 1. A semiquantitative IHC score was adopted as described in the "Methods" section, and scores ranging from 0 (totally negative) to 270 were finally acquired. A median score of 116 was adopted to dichotomize all samples into ALDOA low-expression group and ALDOA high-expression group.

\section{Correlation between ALDOA expression and clinicopathological characteristics}

We analyzed a total of 162 ccRCC patients in the present study. As shown in Table 1, the mean age was $52.6 \pm 10.6$ years old, and 104 (64.2\%) patients were male. The mean tumor 

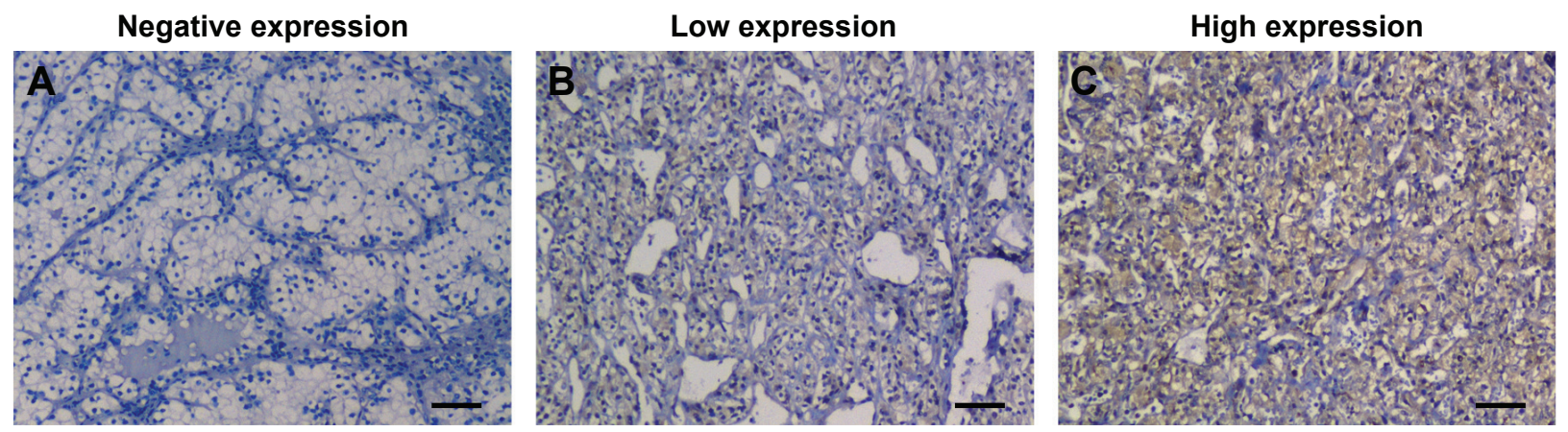

Figure I Representative images of immunohistochemical staining of ALDOA in ccRCC tissues.

Notes: (A) Renal carcinoma tissues showed negative ALDOA staining. (B) Renal carcinoma tissues showed weak ALDOA staining. (C) Renal carcinoma tissues showed strong ALDOA staining. Scale bars, $50 \mu \mathrm{m}$.

Abbreviations: ALDOA, Aldolase A; ccRCC, clear-cell renal cell carcinoma.

Table I Correlation between ALDOA expression and clinicopathological characters in patients with ccRCC

\begin{tabular}{|c|c|c|c|c|}
\hline \multirow[t]{2}{*}{ Variables } & \multirow{2}{*}{$\frac{\text { Patients }}{n=162}$} & \multicolumn{2}{|c|}{ ALDOA expression } & \multirow[t]{2}{*}{$P$-value* } \\
\hline & & Low $(n=82)$ & High $(n=80)$ & \\
\hline Age, year (mean $\pm S D)$ & $52.6 \pm 10.6$ & $52.1 \pm 10.5$ & $53.1 \pm 10.6$ & 0.811 \\
\hline Sex & & & & 0.153 \\
\hline Female & $58,37.7 \%$ & $25,30.5 \%$ & $33,41.3 \%$ & \\
\hline Male & $104,62.3 \%$ & $57,69.5 \%$ & $47,58.8 \%$ & \\
\hline Tumor size, $\mathrm{cm}($ mean $\pm \mathrm{SD})$ & $4.5 \pm 2.5$ & $4.0 \pm 2.3$ & $5.0 \pm 2.6$ & 0.021 \\
\hline TNM stage (AJCC) & & & & 0.034 \\
\hline I & 38 & $26,31.7 \%$ & $12,15.0 \%$ & \\
\hline II & 62 & $32,39.0 \%$ & $30,37.5 \%$ & \\
\hline III & 55 & $22,26.8 \%$ & $33,41.3 \%$ & \\
\hline IV & 7 & $2,2.4 \%$ & $5,6.3 \%$ & \\
\hline pT stage ${ }^{a}$ & & & & 0.148 \\
\hline TI & $42,25.9 \%$ & $27,32.9 \%$ & $15,18.8 \%$ & \\
\hline $\mathrm{T} 2$ & $72,44.4 \%$ & $35,42.7 \%$ & $37,46.3 \%$ & \\
\hline T3 & $41,25.3 \%$ & $18,22.0 \%$ & $23,28.8 \%$ & \\
\hline $\mathrm{T} 4$ & $7,4.3 \%$ & $2,2.4 \%$ & $5,6.3 \%$ & \\
\hline $\mathrm{pN}$ stage $^{\mathrm{a}}$ & & & & 0.020 \\
\hline $\mathrm{N}_{\mathrm{x}}-\mathrm{N} 0$ & $133,82.1 \%$ & $73,89.0 \%$ & $60,75.0 \%$ & \\
\hline $\mathrm{NI}$ & $29,17.9 \%$ & $9,11.0 \%$ & $20,25.0 \%$ & \\
\hline Fuhrman grade & & & & 0.370 \\
\hline I & $44,27.2 \%$ & $25,30.5 \%$ & $19,23.8 \%$ & \\
\hline 2 & $60,37.0 \%$ & $33,40.2 \%$ & $27,33.8 \%$ & \\
\hline 3 & $37,22.8 \%$ & $15,18.3 \%$ & $22,27.5 \%$ & \\
\hline 4 & $21,13.0 \%$ & $9,11.0 \%$ & $12,15.0 \%$ & \\
\hline ISUP/WHO & & & & 0.163 \\
\hline GI & 42 & $25,30.5 \%$ & $17,21.2 \%$ & \\
\hline $\mathrm{G} 2$ & 57 & $32,39.0 \%$ & $25,31.3 \%$ & \\
\hline G3 & 44 & $18,22.0 \%$ & $26,32.5 \%$ & \\
\hline G4 & 19 & $7,8.5 \%$ & $12,15.0 \%$ & \\
\hline Necrosis & & & & 0.644 \\
\hline Absent & $126,77.8 \%$ & $65,79.3 \%$ & $61,76.3 \%$ & \\
\hline Present & $36,22.2 \%$ & $17,20.7 \%$ & $19,23.8 \%$ & \\
\hline MVI & & & & 0.176 \\
\hline Absent & $136,84.0 \%$ & $72,87.8 \%$ & $64,80.0 \%$ & \\
\hline Present & $26,16.0 \%$ & $10,12.2 \%$ & $16,20.0 \%$ & \\
\hline
\end{tabular}

Notes: ${ }^{a}$ The $\mathrm{pT}$ and $\mathrm{pN}$ stages were classified according to $2010 \mathrm{AJCC}$ TNM classification. $*$ Student's $t$-test for continuous variables and $\chi^{2}$-test for categorical variables. Abbreviations: MVI, microvascular invasion; ISUP, International Society of Urological Pathology; SD, standard deviation; WHO, World Health Organization; ALDOA, Aldolase A; AJCC, American Joint Committee on Cancer. 
diameter was $4.5 \pm 2.5 \mathrm{~cm}$, lymph node metastasis was found in 29 patients (17.9\%), and the TNM staging (American Joint Committee on Cancer) distribution was as follows: stage I, 38 patients; stage II, 62 patients; stage III, 55 patients; and stage IV, seven patients. Moreover, histological necrosis was observed in $36(22.2 \%)$ patients, and the number of patients with Fuhrman grades 1, 2, 3, and 4 was 44, 60, 37, and 21, respectively $(27.2 \%, 37.0 \%, 22.8 \%$, and $13.0 \%)$. We also graded cases according to the new International Society of Urologic Pathologists (ISUP)/ World Health Organization (WHO) grading system, ${ }^{21,22}$ and found patients' distribution of G1, G2, G3, and G4 was 42, 57, 44, and 19, respectively $(25.9 \%$, $35.2 \%, 27.2 \%$, and $11.7 \%$ ). There were significant associations between ALDOA expression status with tumor size $(P=0.021)$, TNM stage $(P=0.034)$, and $\mathrm{pN}$ stage $(P=0.020)$.

\section{Prognostic value of ALDOA in ccRCC patients}

To evaluate the association between patient survival and the expression levels of ALDOA, we classified the entire population by high versus low expression levels according to the median IHC score of 116. Kaplan-Meier survival curves for OS, stratified by the ALDOA levels, are shown in Figure 2, the OS being significantly decreased in patients with high levels of ALDOA (Log-rank test, $P<0.001$ ). Multivariate analysis for the predefined variables showed that pT stage, presence of nodal metastases, Fuhrman grade, and ALDOA expression were independent prognostic factors for OS in ccRCC patients (Table 2).

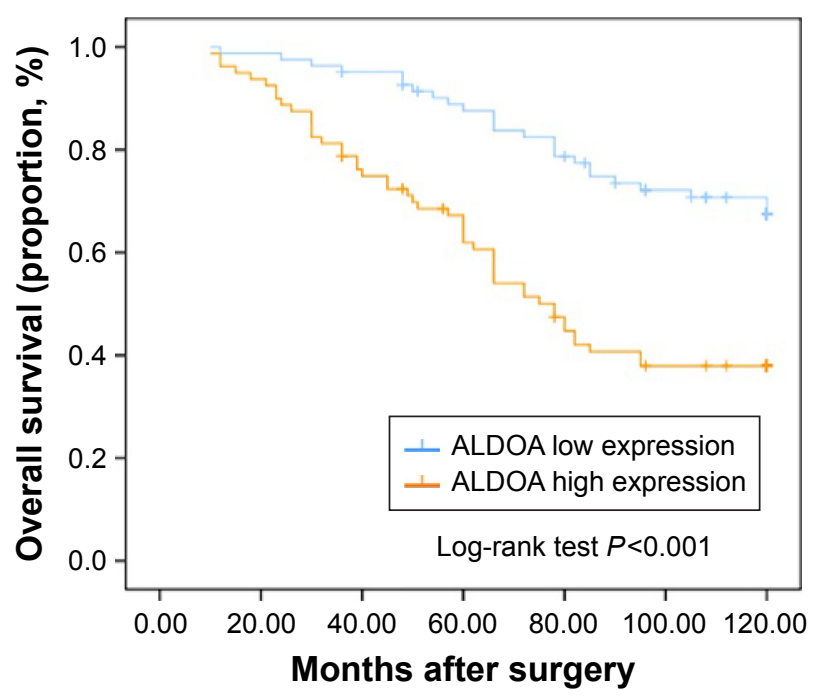

Figure 2 Kaplan-Meier analysis of OS $(n=162)$ of patients with $c c R C C$ based on ALDOA expression.

Note: $P$-value was calculated by log-rank test.

Abbreviations: ALDOA, Aldolase A; OS, overall survival; ccRCC, clear-cell renal cell carcinoma.
In order to further evaluate the prognostic value of ALDOA expression in distinct clinicopathological subgroups, the HRs of ALDOA expression level were investigated in dichotomized TNM stage, T stage, and Fuhrman grade (Figure 3). Since the number of patients with TNM stage IV or pT4 stage was small, we combined them with stage III or pT3 patients. We found that the HR ratio of ALDOA expression for TNM stages was increased as the TNM stage increased. The HR ratio of ALDOA expression for TNM stage I was of no statistical significance, while those for TNM stages II and III + IV were of statistical significance. Similarly, the HR ratio of ALDOA expression for $\mathrm{pT}$ stages was also increased along with the increase in pT stage. The HR ratio of ALDOA expression for $\mathrm{pT} 1$ patients also showed no statistical significance. In addition, we found ALDOA expression was significantly associated with OS in each subgroup of Fuhrman grade without much of a difference in HR ratio among subgroups. Similarly, the ALDOA high expression was also significantly associated with OS in ISUP/ WHO grades 1, 2, 3, and 4 .

\section{Discussion}

In the present study, we examined the expression of ALDOA in ccRCC and evaluated its prognostic value. We confirmed that ALDOA is a predictor of different aggressive tumor behaviors such as advanced $\mathrm{T}$ stage, poorly differentiated carcinoma, and poor survival outcome. Our findings suggested that ALDOA was an independent prognostic factor in patients with ccRCC and that it could serve as a marker and prognostic factor of ccRCC aggressiveness.

Cancer cells rewrite their metabolism pathways to promote and maintain the malignant phenotype. One common feature of the altered metabolism is the increased uptake of glucose and enhancement of glycolysis, even in an aerobic environment. This phenomenon of switching to glycolysis in cancer cells is also known as "the Warburg effect." Recent insights into the biological characteristics of kidney carcinoma suggest that dysregulated metabolic pathways play an important role in many subtypes of this malignance. In ccRCC, comprehensive molecular characterization of this subtype displayed a shift to altered use of metabolites toward a "Warburg effect"-like state. ${ }^{23}$ ALDOA is a ubiquitous glycolytic enzyme that drives the glycolytic metabolic pathway in mammalian cells. Aberrant expression of ALDOA was found in various cancers, ${ }^{15,17,18}$ suggesting enhanced glycolysis in these cancer cells. Abnormal expression of ALDOA was also observed in renal carcinoma by a recent proteotranscriptomic study, which revealed that ALDOA were decreased at early stages relative 
Table 2 Univariate and multivariate Cox regression analysis of OS in 162 ccRCC patients

\begin{tabular}{|c|c|c|c|c|c|c|}
\hline \multirow[t]{2}{*}{ Variables } & \multicolumn{3}{|c|}{ Univariate } & \multicolumn{3}{|c|}{ Multivariate } \\
\hline & HR & $95 \% \mathrm{Cl}$ & $P$-value & HR & $95 \% \mathrm{Cl}$ & $P$-value \\
\hline Age & 1.088 & $0.942-1.257$ & 0.251 & & & \\
\hline Sex & & & $0.56 \mathrm{I}$ & & & \\
\hline Male & & Reference & & & & \\
\hline Female & 0.987 & $0.956-1.019$ & & & & \\
\hline Tumor size, cm & 1.216 & $1.011-1.426$ & 0.038 & 1.134 & $0.95 \mathrm{I}-1.352$ & 0.161 \\
\hline \multicolumn{7}{|l|}{ PT stage } \\
\hline pTI & & Reference & & & Reference & \\
\hline pT2 & 2. 107 & $1.126-3.943$ & 0.020 & 1.565 & $1.039-2.357$ & 0.032 \\
\hline PT3 & 3.215 & $1.017-10.163$ & 0.048 & 1.991 & $0.879-4.512$ & 0.099 \\
\hline PT4 & 4.812 & $0.512-45.225$ & 0.169 & 3.583 & $0.225-57.006$ & 0.366 \\
\hline \multicolumn{7}{|l|}{$\mathrm{pN}$ stage } \\
\hline $\mathrm{pNx}+\mathrm{pN} 0$ & & Reference & & & Reference & \\
\hline $\mathrm{pNI}$ & 8.912 & $3.162-25.118$ & 0.001 & 5.634 & $|.34|-23.670$ & 0.018 \\
\hline \multicolumn{7}{|l|}{ Fuhrman grade } \\
\hline I & & Reference & & & Reference & \\
\hline 2 & 1.316 & $0.911-1.901$ & 0.143 & 1.436 & $1.002-2.059$ & 0.049 \\
\hline 3 & 2.431 & I.432-4.I26 & 0.001 & 2.742 & $1.511-4.976$ & 0.001 \\
\hline 4 & 5.712 & $1.491-21.885$ & 0.011 & 4.537 & $1.282-16.054$ & 0.019 \\
\hline \multicolumn{7}{|l|}{ ISUP/WHO } \\
\hline GI & & Reference & & & Reference & \\
\hline G2 & 1.391 & $1.010-1.915$ & 0.043 & 1.511 & $1.038-2.199$ & 0.031 \\
\hline G3 & 2.266 & $1.399-3.670$ & 0.001 & 2.512 & I.458-4.327 & 0.001 \\
\hline G4 & 5.266 & $1.610-17.223$ & 0.006 & 4.611 & $1.399-15.195$ & 0.012 \\
\hline \multicolumn{7}{|l|}{ Necrosis } \\
\hline Absent & & Reference & & & Reference & \\
\hline Present & 1.423 & $1.025-2.238$ & 0.037 & 1.199 & $0.760-1.893$ & 0.436 \\
\hline \multicolumn{7}{|l|}{ MVI } \\
\hline Absent & & Reference & & & Reference & \\
\hline Present & 1.423 & $1.025-2.238$ & 0.037 & 1.275 & $0.906-1.794$ & 0.291 \\
\hline \multicolumn{7}{|l|}{ ALDOA expression } \\
\hline Low expression & & Reference & & & Reference & \\
\hline High expression & 3.788 & $2.016-7.118$ & 0.001 & $3.56 \mathrm{I}$ & $1.715-7.396$ & 0.001 \\
\hline
\end{tabular}

Abbreviations: MVI, microvascular invasion; HR, hazard ratio; Cl, confidence interval; ISUP, International Society of Urological Pathology; WHO, World Health Organization; ALDOA, Aldolase A; OS, overall survival.

to normal tissue but increased at later stages. ${ }^{13}$ However, the prognostic value of ALDOA in renal carcinoma remained unknown. In view of the important role of ALDOA in glycolysis, here we assessed the clinical significance of ALDOA expression in ccRCC and found ALDOA was an independent prognostic factor for OS in patients with ccRCC.

ALDOA expression has been reported to be significantly elevated relative to other glycolytic enzymes in a number of human tumor types. ${ }^{16,24}$ In regard to biological functions, ALDOA has been identified as an oncogene in cancers such as, lung cancer, ${ }^{15,16}$ pancreatic ductal adenocarcinoma, ${ }^{17}$ and hepatocellular carcinomas. ${ }^{18}$ ALDOA was involved in the regulation of cell viability, proliferation ability, and metastasis capacity of many cancer cells; it also participated in activating signal pathways associated with tumorigenesis. ${ }^{25}$ A recent study reported that ALDOA was a key target for inhibiting both glycolysis and HIF1 activity, ${ }^{26}$ the two important targets of renal carcinoma. ${ }^{27}$ Therefore, it would be appropriate to speculate that ALDOA might also promote progression of renal carcinoma. In the present study, we found that ALDOA expression was increased along with elevated $\mathrm{T}$ stage, which was consistent with a previous study. ${ }^{13}$ ALDOA expression was less observed in the lower stages, and ALDOA seemed to correlate with OS in every stage except stage I. These findings suggested that ALDOA may also function as an oncogene in ccRCC and play an increasingly important role following tumor progression. Further exploration is warranted to clarify the pathophysiological mechanism of ALDOA in ccRCC.

\section{Conclusion}

In summary, the present study showed that ALDOA expression in tumor tissue was a potential independent predictive factor for OS in patients with nonmetastatic ccRCC, and ALDOA might be have a pivotal role in the progression of ccRCC. This study was limited by the retrospective design, 


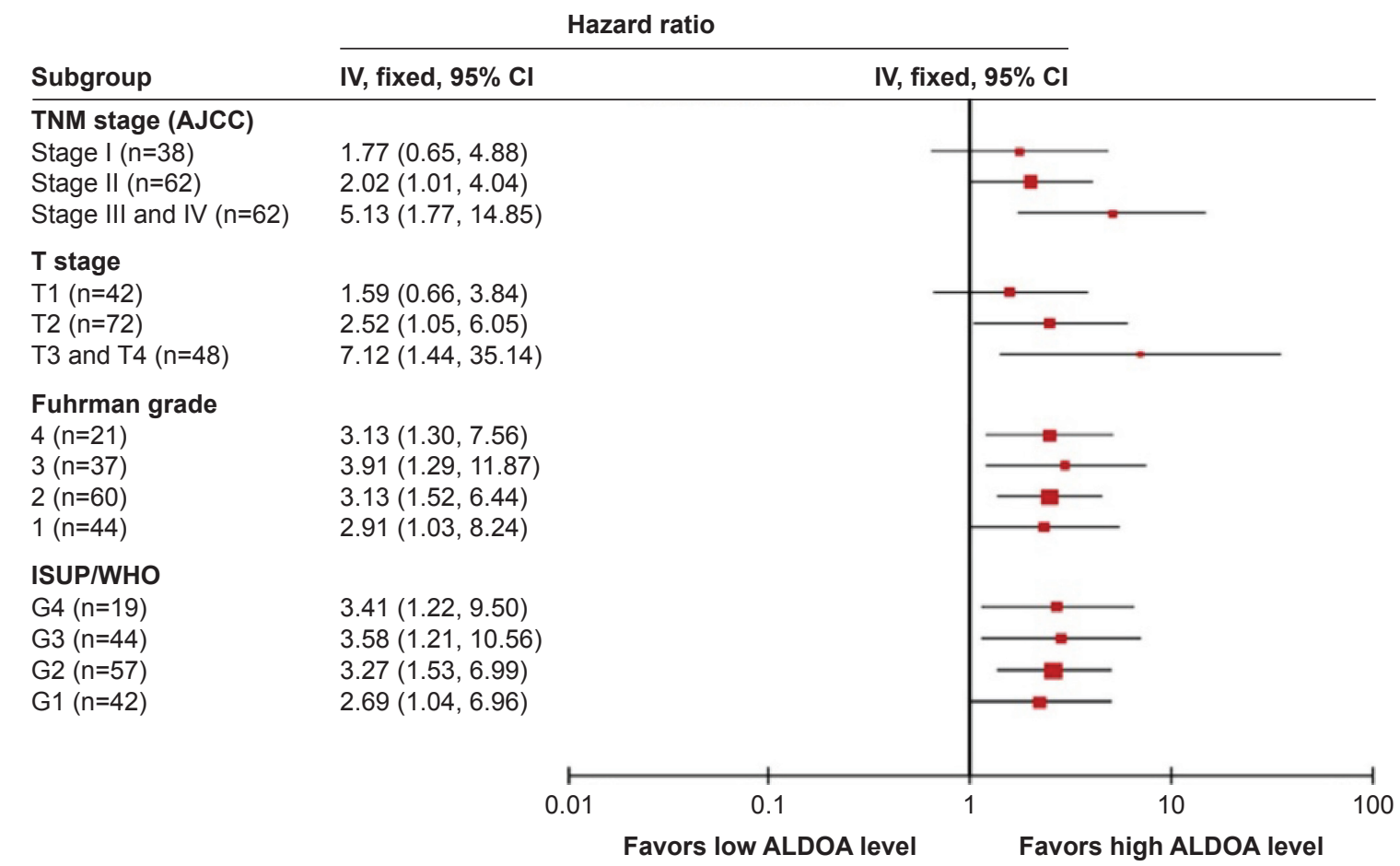

Figure 3 Subgroup analysis of ALDOA expression for OS among ccRCC patients classified by TNM stages, pT stages, and Fuhrman grade with results expressed using hazard ratios.

Abbreviations: AJCC, American Joint Committee on Cancer; ALDOA, Aldolase A; ccRCC, clear-cell renal cell carcinoma; Cl, confidence interval; ISUP, International Society of Urological Pathology; OS, overall survival; WHO, World Health Organization.

and further prospective multicenter studies and laboratory investigations are required to confirm our results and provide additional evidence for the roles of ALDOA in ccRCC patients.

\section{Acknowledgments}

This study was supported by the Natural Science Foundation of China (81470977). The authors are very grateful to Dr Shicong Yang for assistance in the evaluation of the pathological condition of specimens.

\section{Author contributions}

Q Jiang conceived the study, and Q Jiang and N Na drafted the manuscript. H Li and CF Xu performed the immunohistochemical examination of the sections and were major contributors in writing the final manuscript. B Miao, LQ Hong, and ZY Huang analyzed and interpreted the patient data. All authors contributed toward data analysis, drafting and critically revising the paper and agree to be accountable for all aspects of the work.

\section{Disclosure}

The authors report no conflicts of interest in this work.

\section{References}

1. Motzer RJ, Bander NH, Nanus DM. Renal-cell carcinoma. $N$ Engl $J$ Med. 1996;335(12):865-875.

2. Battaglia M, Lucarelli G. The role of renal surgery in the era of targeted therapy: the urologist's perspective. Urologia. 2015;82(3):137-138.

3. Tunuguntla HS, Jorda M. Diagnostic and prognostic molecular markers in renal cell carcinoma. J Urol. 2008;179(6):2096-2102.

4. Ng KL, Morais C, Bernard A, et al. A systematic review and metaanalysis of immunohistochemical biomarkers that differentiate chromophobe renal cell carcinoma from renal oncocytoma. J Clin Pathol. 2016;69(8):661-671.

5. Volpe A, Patard JJ. Prognostic factors in renal cell carcinoma. World J Urol. 2010;28(3):319-327.

6. McGuire BB, Fitzpatrick JM. Biomarkers in renal cell carcinoma. Curr Opin Urol. 2009;19(5):441-446.

7. Fu H, Liu Y, Xu L, et al. Low expression of Mucin-4 predicts poor prognosis in patients with clear-cell renal cell carcinoma. Medicine (Baltimore). 2016;95(17):e3225.

8. Vander Heiden MG, Cantley LC, Thompson CB. Understanding the Warburg effect: the metabolic requirements of cell proliferation. Science. 2009;324(5930):1029-1033.

9. Chen XS, Li LY, Guan YD, Yang JM, Cheng Y. Anticancer strategies based on the metabolic profile of tumor cells: therapeutic targeting of the Warburg effect. Acta Pharmacol Sin. 2016;37(8):1013-1019.

10. Shuch B, Linehan WM, Srinivasan R. Aerobic glycolysis: a novel target in kidney cancer. Expert Rev Anticancer Ther. 2013;13(6):711-719.

11. Sanders E, Diehl S. Analysis and interpretation of transcriptomic data obtained from extended Warburg effect genes in patients with clear cell renal cell carcinoma. Oncoscience. 2015;2(2):151-186.

12. Zaravinos A, Pieri M, Mourmouras N, et al. Altered metabolic pathways in clear cell renal cell carcinoma: a meta-analysis and validation study focused on the deregulated genes and their associated networks. Oncoscience. 2014;1(2):117-131. 
13. Neely BA, Wilkins CE, Marlow LA, et al. Proteotranscriptomic analysis reveals stage specific changes in the molecular landscape of clear-cell renal cell carcinoma. PLoS One. 2016;11(4):e0154074.

14. Kajita E, Moriwaki J, Yatsuki H, et al. Quantitative expression studies of aldolase A, B and $\mathrm{C}$ genes in developing embryos and adult tissues of Xenopus laevis. Mech Dev. 2001;102(1-2):283-287.

15. Kycko A, Reichert M. Overexpression of aldolase A and cytokeratin 19 in ovine pulmonary adenocarcinoma. Pol J Vet Sci. 2012;15(4): 703-709.

16. Du S, Guan Z, Hao L, et al. Fructose-bisphosphate aldolase a is a potential metastasis-associated marker of lung squamous cell carcinoma and promotes lung cell tumorigenesis and migration. PLoS One. 2014;9(1):e85804.

17. Ji S, Zhang B, Liu J, et al. ALDOA functions as an oncogene in the highly metastatic pancreatic cancer. Cancer Lett. 2016;374(1):127-135.

18. Castaldo G, Calcagno G, Sibillo R, et al. Quantitative analysis of aldolase A mRNA in liver discriminates between hepatocellular carcinoma and cirrhosis. Clin Chem. 2000;46(7):901-906.

19. Takashi M, Zhu Y, Nakano Y, Miyake K, Kato K. Elevated levels of serum aldolase A in patients with renal cell carcinoma. Urol Res. 1992; 20(4):307-311.

20. Zhu YY, Takashi M, Miyake K, Kato K. An immunochemical and immunohistochemical study of aldolase isozymes in renal cell carcinoma. J Urol. 1991;146(2):469-472.
21. DelahuntB, EgevadL, Samaratunga H, Martignoni G, Nacey JN, Srigley JR Gleason and Fuhrman no longer make the grade. Histopathology. 2016;68(4):475-481.

22. Moch H. [The WHO/ISUP grading system for renal carcinoma]. Pathologe. 2016;37(4):355-360. German.

23. Cancer Genome Atlas Research N. Comprehensive molecular characterization of clear cell renal cell carcinoma. Nature. 2013;499(7456): 43-49.

24. Oparina NY, Snezhkina AV, Sadritdinova AF, et al. [Differential expression of genes that encode glycolysis enzymes in kidney and lung cancer in humans]. Genetika. 2013;49(7):814-823. Russian.

25. Caspi M, Perry G, Skalka N, et al. Aldolase positively regulates of the canonical Wnt signaling pathway. Mol Cancer. 2014;13:164.

26. Grandjean G, de Jong PR, James BP, et al. Definition of a novel feedforward mechanism for glycolysis-HIF1alpha signaling in hypoxic tumors highlights aldolase A as a therapeutic target. Cancer Res. 2016; 76(14):4259-4269.

27. Schodel J, Grampp S, Maher ER, et al. Hypoxia, hypoxia-inducible transcription factors, and renal cancer. Eur Urol. 2016;69(4):646-657.
Therapeutics and Clinical Risk Management

\section{Publish your work in this journal}

Therapeutics and Clinical Risk Management is an international, peerreviewed journal of clinical therapeutics and risk management, focusing on concise rapid reporting of clinical studies in all therapeutic areas, outcomes, safety, and programs for the effective, safe, and sustained use of medicines. This journal is indexed on PubMed Central, CAS,

\section{Dovepress}

EMBase, Scopus and the Elsevier Bibliographic databases. The manuscript management system is completely online and includes a very quick and fair peer-review system, which is all easy to use. Visit http://www.dovepress.com/testimonials.php to read real quotes from published authors.

Submit your manuscript here: http://www.dovepress.com/therapeutics-and-clinical-risk-management-journal 